\title{
Pleasing some of the people
}

Paris

A REPORT* just published by the UK House of Commons Foreign Affairs Select Committee, chaired by Foreign Office under-secretary Timothy Sainsbury, says there is "no reason why the UK should not rejoin" the United Nations Educational, Scientific and Cultural Organisation (UNESCO) in 12 months if there is "real evidence of improvement". Britain and Singapore left UNESCO in 1985, a year after the United States withdrew, all in protest at the policies of the previous director-general, AmadouMahdar M'Bow.

But since the beginning of March, when the committee heard evidence from Federico Mayor, UNESCO's present director-general, Mayor has announced reforms which have rocked the boat again.

A freeze on recruitment and the filling of vacancies angered some staff to the extent that they stopped work for two hours last week, complaining of a lack of consultation. In future, all new appointments will have to be approved by Mayor himself, while a new policy of decentralization will mean transfers abroad and fewer staff at the Paris headquarters. According to one source close to Mayor, most of the internal complaints were from members of a staff union appointed by M'Bow.

In addition, plans to appoint more than 20 senior programme co-ordinators and consultants have upset some US diplomats, who see them as going against earlier promises to cut costs. But according to estimates from within UNESCO, the new posts will cost about $\$ 3.5$ million over two years, while savings made through previous staff cuts and the new freeze have been estimated to reach $\$ 18$ million by 1993 .

One appointment in particular has provoked criticism from US observers. As co-ordinator for communication and information, Mayor has chosen Henrikh Yushkiavitshus, former deputy director of the Soviet State Commission on Radio and Television. The potential for censorship in the guise of information management was one of the chief issues that led to the US withdrawal from UNESCO. But, say those inside UNESCO, Yushkiavitshus has been behind efforts to liberate the Soviet media in recent years, and he is said to be liked by Western journalists.

Some of the reforms follow recommendations of an international commission chaired by Knut Hammarskjöld, and subsequent comments by a panel of experts headed by Peter Wilenski, in reports delivered to Mayor at the end of 1989. The number of UNESCO programmes has been reduced from 52 to 18 , while the new co-ordinator posts are an attempt to place talented individuals, sometimes brought in from outside UNESCO, in leading posts.

The new jobs are intended to achieve a more efficient management structure. In his policy document, Mayor launches an whole-hearted attack on the present administration. "UNESCO has become too rigid", he says, "a large slow-moving body, made up of staff too often weighed down by administrative tasks and who in many cases no longer work in the forefront of knowledge or of their own special field." He goes on to compare this structure to "a brain, proportionally reduced, with poor means of anticipation and orientation, and few, or no, alarm mechanisms".

According to one senior UNESCO official, the reforms were bound to attract resistance. "If Mayor had announced these policies two years ago, everyone would have said 'bravo', he's a man of action. Leaner structures may be hard for some, but they are necessary."

Though the United States remains lukewarm, the new reforms have received a partly positive response in London. A spokesman for the Foreign Affairs Select Committee confirmed that the government would stick to its decision to "wait and see" over the next 12 months. The changes have gone "a long way" in terms of programmes, but are said to be "limited" in terms of administration, he said. Meanwhile, the new expansion plans seemed "uncertain and confusing", but, he added, "more time is needed to see whether the director-general can deliver".

Peter Coles

*UK Policy on UNESCO (House of Commons Paper 255. Vol. 1 1989-90 Session.)

\section{AGEING Setting the memory norm}

\section{Washington}

EARLY results from a study on memory loss in the inhabitants of half a dozen small Italian towns are providing data of unprecedented accuracy on rates of neurological deterioration. Project scientists hope that the survey will establish with far greater precision what "normal" memory loss is, in part to distinguish it from the early symptoms of Alzheimer's disease. Previous studies have suggested that between the age of 30 and 60 , normal adults may exhibit a 60 per cent decline in name and face recognition.

The main sponsor of Progetto Memoria (Memory Project) is the Memory Reseach Centre of the Italian pharmaceutical company Fidia. The project is expected to establish baseline measurements of memory loss with statistical errors of as little as two per cent, an accuracy which Fidia scientists attribute largely to Italy's stationary population.

Because most people in the survey live in the place they were born, the scientists are studying an unusually homogeneous cross-section of the population, says Thomas Crook, president of the US-based Memory Assessment Clinic, which is participating in the project. Average rates of change in the population of the selected towns are as little as a few tenths of a per cent per year, Crook says. Most US populations are far more mobile, and less homogeneous, than their Italian counterparts.

"In the United States it's difficult to know who stayed and who left. Is the [remaining population] in a certain city the sickest or the best?", Crook asks. Although 5,000 Americans 50 years of age and older have had their memory tested by various methods in recent years, the surveys have traditionally been tests of people who come to researchers with concerns about their memory. Such "samples by convenience" may exhibit systematic biases, says Crook.

Because Italy has a national health care system with comprehensive health records and a regularly-updated census, "the whole first step in standard epidemiology is done for us," says Francesco Grigoletto, a statistician from the University of Padua, Italy.

Progetto Memoria is travelling through Italy in a $\$ 450,000$ mobile testing laboratory. The scientists enlist local media and physicians to publicize the arrival of the team and to explain its objectives. Then the team places the mobile testing laboratory at the centre of each day's survey area.

Early results show that only 10 to 15 per cent of the selected population refuses to participate in the voluntary survey, and project scientists expect about 75 per cent overall participation by the end of the survey. Over 1,600 normal, healthy Italians between 20 and 79 years of age will be tested by the time the project is finished at the end of the year.

The survey uses tests specially designed to be independent of cultural, educational, or economic bias. In one test subjects are shown videotapes of between 2 and 14 people who introduce themselves and give some basic personal information, such as the name of their hometown. The participants are then shown the faces alone, and are asked to recall the correct names and personal details.

Other tests involve following a maze or recalling the location of everyday objects such as eyeglasses or keys. 